\title{
Low-Density Polyethylene Nanocomposite Containing Zn/Ti Layered Double Hydroxide
}

\author{
Silvia Jaerger", Daiane Amaral de Ramos Nogueira, Douglas Santos de Oliveira, Monielly \\ Viomar Machado and Rafael Marangoni
}

\author{
Universidade Estadual do Centro-Oeste, Campus CEDETEG, Departamento de Química, 85040-080, \\ Guarapuava, Paraná, Brazil
}

\begin{abstract}
The presented work shows the synthesis and characterization of $\mathrm{Zn} / \mathrm{Ti}$ layered double hydroxide (LDH) intercalated with carbonate and dodecyl sulfate ions following its application as a functional filler in LDPE in order to improve the thermal properties and resistance degradation in UV-Vis radiation. X-ray diffractogram patterns of $\mathrm{Zn} / \mathrm{Ti}$ $\mathrm{LDH}-\mathrm{CO}_{3}$ and $\mathrm{Zn} / \mathrm{Ti} \mathrm{LDH}-\mathrm{DDS}$ present basal spacing value in the order of $6.81 \AA$ and $38.09 \AA$, respectively, indicating success in layered compound synthesis. LDPE nanocomposite containing hydrophobic and hydrophilic LDH presented a very well dispersed nanocomposite, as demonstrated in XRD and DSC results. The addition of only $1 \%$ of LDH as filler into LDPE causes an increase of $5.43{ }^{\circ} \mathrm{C}$ in the thermal property. $\mathrm{Zn} / \mathrm{Ti} \mathrm{LDH}$-DDS absorbs more light compared to the $\mathrm{Zn} / \mathrm{Ti} \mathrm{LDH}-\mathrm{CO}_{3}$ due to the enhanced interlayer distance in the presence of DDS in the basal space of LDH, which further the intercalation process of polymer chains within the interlayer regions of LDH.
\end{abstract}

Keywords: Zn/Ti layered double hydroxide, low-density polyethylene, nanocomposite, UV-Vis photodegradation.

\section{INTRODUCTION}

Low-density polyethylene (LDPE) has superior properties in durability and low weight, so LDPE offers several advantages in the automotive industry, such as fuel-saving, chemical resistance, ease of processing, corrosion resistance, and electrical insulation [1]. LDPE-based products are often used outdoors, which in most cases causes their exposure to sunlight and makes them susceptible to photodegradation. Polymeric structures exposed to ultraviolet (UV) light are subjected to photodegradation, causing color changes as a result of changes in their chemical surface, in addition to affecting the mechanical, physical, and chemical properties of their structure. The photodegradation caused by UV rays occurs in the form of oxidation, chain shrinkage, and molecule degradation [1]. To avoid the degradation of polymeric materials, the strategy is to reduce the damage caused by radiation and suppress radicals' formation. This can be achieved using ultraviolet light absorbers, hydroxide decomposers, and radical scavengers [2].

Several UV absorbers are used as additives in polymers, including organic and inorganic UV absorbers. The first compound can absorb energy from sunlight and dissipate it as heat, which promotes thermal degradation of the polymer matrix, and some of these compounds can leak from the matrix and cause

*Address correspondence to this author at the State University of the Midwest, campus CEDETEG, Guarapuava, Paraná, Brazil; Tel: 55-42-3629-8301; E-mail: sjaerger@gmail.com severe damage to the environment because they are not environmentally friendly [2]. The most used inorganic UV absorbers, $\mathrm{TiO}_{2}$ and $\mathrm{ZnO}$, are more thermally stable than the organic absorbers; however, they are relatively large, making the polymer composite non-transparent and causing a severe decrease in the mechanical strength of the polymers when used alone. A strategy to overcome the shortcomings of both types of additives is combining them in a single compound to optimize their properties. To circumvent this problem, a well-known type of anionic clay can be used for this purpose, the layered double hydroxides (LDH).

The LDH has a general formula $\left[\mathrm{M}^{\prime \prime}{ }_{1-\mathrm{x}} \mathrm{M}^{\prime \prime \prime \prime}{ }_{\mathrm{x}}(\mathrm{OH})_{2}\right]$ $\left(\mathrm{A}^{\mathrm{n}-}\right)_{\mathrm{x} / \mathrm{n}} \cdot \mathrm{mH}_{2} \mathrm{O}$, where $\mathrm{M}^{\prime \prime}$ and $\mathrm{M}^{\prime \prime \prime}$ are divalent and trivalent metals respectively, $A^{n-}$ symbolizes various interlayer anions, $\mathrm{m}$ is the moles of water molecules located in the interlayer galleries together with the anions [3]. The di- and tri- valent cations, the interlayer space anions, and the stoichiometric coefficient $(x)$ can be varied over a wide range, which gives rise to a large class of isostructural materials that have been extensively explored in different fields such as catalysis, separation, electrode materials, polymer additives and functional additives [3]. This type of material is the best option to obtain the desired properties for different types of polymers. Combinations of inorganic cations and organic anions (host-guest) function as functional additives for polymers, resulting in polymers' manufacture as multifunctional compounds.

The uniform way in which the metals $\mathrm{M}^{\prime \prime}$ and $\mathrm{M}^{\mathrm{III}}$ or $M^{\mathrm{IV}}$ are distributed in the hydroxide layers of the LDH 
without the appearance of clusters is an important structural characteristic of UV absorber materials. The structure of LDH is based on layers of the edge-shared $\mathrm{MO}_{6}$ octahedron similar to the mineral brucite $\mathrm{Mg}(\mathrm{OH})_{2}$. One of the main factors affecting the photophysical system and photocatalytic properties of LDH is how the layer is arranged in the form of the $\mathrm{MO}_{6}$ octahedron. Another factor that shows high photocatalytic efficiency is the high degree of dispersion of the transition metal; this allows the electron to be transferred and prevents the recombination of electrons and holes [4].

In recent years, strategies of synthesis and use of $\mathrm{Zn} / \mathrm{Ti} \mathrm{LDH}$ with photocatalysis performance were often reported in the specialized literature. In 2019, Fang et al. investigated the enhanced photocatalytic performance of $\mathrm{Zn} / \mathrm{Ti} \mathrm{LDHs}$ with morphology control. The results showed that the type of surfactant could affect the morphology of $\mathrm{Zn} / \mathrm{Ti} \mathrm{LDHs}$. An anionic surfactant (sodium dodecyl sulfate) used $\mathrm{Zn} / \mathrm{Ti} \mathrm{LDHs}$ synthesis with flower-like structures help in obtained self-assembly of sheets layered structure. The synthesis method used was the surfactant-assisted hydrothermal method, the same used in this work. This study's authors affirmed that the self-assembled $\mathrm{Zn} / \mathrm{Ti}$ $\mathrm{LDH}$ particles exhibit excellent photocatalytic performances in methyl orange degradation when P123 is added into the solution as a surfactant [3]. In 2018, Naseem et al. investigated different transition metal combinations of LDH systems and their organic modifications as UV protecting materials for polypropylene (PP). The authors studied the use of different $\mathrm{LDH}$, such as $\mathrm{Zn} / \mathrm{Ti}, \mathrm{Zn} / \mathrm{Sn}, \mathrm{Zn} / \mathrm{Ga}, \mathrm{Zn} / \mathrm{Cr}$, and $\mathrm{Cd} / \mathrm{Cr} \mathrm{LDHs}$ organically modified with dodecylbenzene sodium sulfonate (SDBS) and lauric acid (LA), as ultraviolet (UV) light-protecting additives for PP [2]. $\mathrm{Zn} / \mathrm{Ti} \mathrm{LDHs}$ by varying cationic ratio of $\mathrm{Ti}^{4+}$ and its application as UV absorbent were fabricated by Wang et al. in 2017. The results demonstrated that $\mathrm{Zn} / \mathrm{Ti}$ LDHs have high crystallinity and hierarchical structure with improved UV-absorbance property, and UV-Vis spectra show that the UV absorbing properties of $\mathrm{Zn} / \mathrm{Ti}$ LDHs are stronger and broader than both MgAl-LDH and $\mathrm{Zn} / \mathrm{Ti} \mathrm{LDHs}$ due to the existence of $\mathrm{Ti}$ [5]. The new titanium embedded LDH was produced by Lee et al. in 2010 as highly efficient water oxidation photocatalysts under visible light. The study demonstrated that the two kinds of LDHs (Ni/Ti LDH and $\mathrm{Cu} / \mathrm{Ti} \mathrm{LDH}$ ) has two absorption bands in the red and blue regions under visible light, thus different from those of a pure metal oxide with absorption bands in only the UV region. Therewith, this new structure implies that absorption bands in the visible range and the large surface area of an LDH could result in the high-water oxidation photocatalytic activity under visible light [6]. With this innovative study, it was possible to open a range of opportunities to apply these new materials as photocatalytic in different areas. However, there are still few studies using LDH containing titanium in its structure to prevent UV aging of polymers.

This current study will present several characterizations of $\mathrm{Zn} / \mathrm{Ti} \mathrm{LDHs}$ structures, and their use as UV adsorbed material as filler into low-density polyethylene. The use of LDH containing titanium in its structure will overcome some disadvantage in the use of inorganic UV adsorbed $\left(\mathrm{TiO}_{2}\right.$ and $\left.\mathrm{ZnO}\right)$, especially due to its high degree of dispersion of the transition metal, allowing the transfer of electrons and preventing the recombination of electrons and holes as described in Mohapatra and Parida (2016) study [4].

In this sense, the objective of the presented work is to synthesize $\mathrm{LDH}$ of $\mathrm{Zn}$ and $\mathrm{Ti}$ in the molar ratio $4: 1$ (Zn:Ti) intercalated with carbonate and dodecyl sulfate ions following its application as a functional filler in LDPE in order to improve the thermal properties and resistance degradation in UV-Vis radiation.

\section{EXPERIMENTAL}

\section{Materials}

For LDH synthesis were used the following reagents: zinc chloride $\mathrm{ZnCl}_{2} \cdot 6 \mathrm{H}_{2} \mathrm{O}\left(297.49 \mathrm{~g} \mathrm{~mol}^{-1}\right)$, titanium chloride $\mathrm{TiCl}_{4}\left(189,679 \mathrm{~g} \mathrm{~mol}^{-1}\right)$, and urea $\left(\mathrm{CH}_{4} \mathrm{~N}_{2} \mathrm{O}, 60.06 \mathrm{~g} \mathrm{~mol}^{-1}\right)$ were supplied by Sigma Aldrich and sodium dodecyl sulfate salt $\left(\mathrm{NaC}_{12} \mathrm{H}_{25} \mathrm{SO}_{4}\right.$, $288.38 \mathrm{~g} \mathrm{~mol}^{-1}$ ) was supplied by Tokyo Chemical Industry. All chemicals used in this study were of analytical-laboratory grade (Table 1).

For LDPE nanocomposite containing $\mathrm{Zn} / \mathrm{Ti} \mathrm{LDH}$ maleic anhydride grafted linear LDPE LDPE-g-MAH (density $0.926 \mathrm{~g} \mathrm{~cm}^{-3}$, melt flow index (MFI) $30.0 \mathrm{~g} / 10$ min, maleic anhydride level $1.0 \mathrm{wt} \%$ ) and neat LDPE (density $0.926 \mathrm{~g} \mathrm{~cm}^{-3}$, MFI $30.0 \mathrm{~g} / 10 \mathrm{~min}$ ) polymers obtained from ExxonMobil were used. Where LDPE-g$M A H$ was used for the masterbatch process and neat LDPE for preparation of the nanocomposites, as demonstrated in Table 2.

\section{$\mathrm{Zn} / \mathrm{Ti}$ Layered Double Hydroxide Synthesis and Nanocomposite Preparation}

$\mathrm{Zn} / \mathrm{Ti} \mathrm{LDH}$ was prepared by the urea synthesis method, which consists of a mixture of $200 \mathrm{~mL}$ of the 
Table 1: Reagents Used for LDH Synthesis

\begin{tabular}{|c|c|c|}
\hline \multicolumn{2}{|c|}{ LDH synthesis } & \multirow{2}{*}{ Characterizations } \\
\hline LDH & Reagents & \\
\hline $\mathrm{Zn} / \mathrm{Ti} \mathrm{LDH}-\mathrm{CO}_{3}$ & $\mathrm{ZnCl}_{2} \cdot 6 \mathrm{H}_{2} \mathrm{O}, \mathrm{TiCl}_{4}$ and $\mathrm{CH}_{4} \mathrm{~N}_{2} \mathrm{O}$ & \multirow{2}{*}{$\begin{array}{l}\text { X-Ray Diffractograms (XRD), Fourier-transform infrared spectra } \\
\text { (FTIR), thermogravimetric analysis (TGA), transmission electron } \\
\text { microscopic (TEM) images and selected area electron diffraction } \\
\text { analyzes (SAED). }\end{array}$} \\
\hline Zn/Ti LDH-DDS & $\begin{array}{c}\mathrm{ZnCl} \cdot 6 \mathrm{H}_{2} \mathrm{O}, \mathrm{TiCl}_{4}, \mathrm{CH}_{4} \mathrm{~N}_{2} \mathrm{O} \text { and } \\
\mathrm{NaC}_{12} \mathrm{H}_{25} \mathrm{SO}_{4}\end{array}$ & \\
\hline
\end{tabular}

Table 2: Filler Content and Polymer Used in LDPE Nanocomposite Preparation

\begin{tabular}{|c|c|c|c|c|}
\hline Process & Filler / Filler content & Polymer & $\begin{array}{c}\text { Name of the } \\
\text { composite }\end{array}$ & Characterizations \\
\hline \hline Masterbatch & $\begin{array}{c}\mathrm{Zn} / \mathrm{Ti} \mathrm{LDH}-\mathrm{CO}_{3} \text { and } \mathrm{Zn} / \mathrm{Ti} \\
\mathrm{LDH}-\mathrm{DDS} / 1: 3 \text { (filler: } \\
\text { polymer) }\end{array}$ & LDPE-g-MAH & $\begin{array}{c}\mathrm{PG}-\mathrm{LDH}-\mathrm{CO}_{3} \text { and } \\
\mathrm{PG}-\mathrm{LDH}-\mathrm{DDS}\end{array}$ & \\
\hline $\begin{array}{c}\text { Nanocomposite } \\
\text { preparation }\end{array}$ & $\begin{array}{c}\mathrm{PG}-\mathrm{LDH}-\mathrm{CO}_{3} \text { and PG-LDH- } \\
\mathrm{DDS} / 8.5 \% \text { of filler and } 91.5 \\
\% \text { of polymer }\end{array}$ & LDPE & $\begin{array}{c}\text { PE-LDH-CO } \text { and }_{3} \\
\text { PE-LDH-DDS }\end{array}$ & $\begin{array}{c}\text { X-Ray Diffractograms (XRD), Fourier- } \\
\text { transform infrared spectra (FTIR), } \\
\text { thermogravimetric analysis (TGA), differential } \\
\text { scanning calorimetric (DSC) experiments and } \\
\text { accelerated weathering including a constant } \\
\text { UV exposure light }\end{array}$ \\
\hline
\end{tabular}

salts' solution containing $80 \mathrm{mmol}$ of zinc chloride, 20 $\mathrm{mmol}$ of titanium chloride, and $80 \mathrm{mmol}$ of urea. This solution was placed in a round bottom flask under reflux for $24 \mathrm{~h}$ at $100^{\circ} \mathrm{C}$. The white solid formed was filtered off, washed several times, and dried in a vacuum oven at $60^{\circ} \mathrm{C}$ for $24 \mathrm{~h}$.

After drying, the LDH was subjected to an ionexchange reaction, where its counterions were exchanged for the dodecyl sulfate anion. For this, 300 $\mathrm{ml}$ of a solution containing $70 \mathrm{mmol}$ of dodecyl sulfate was prepared, to which $3.0 \mathrm{~g}$ of LDH was added. This reaction remained under constant magnetic stirring for $24 \mathrm{~h}$. The final solid was filtered off, washed, and dried in a vacuum oven at $60{ }^{\circ} \mathrm{C}$ for $24 \mathrm{~h}$. Thus, were prepared two types of $\mathrm{Zn} / \mathrm{Ti} \mathrm{LDH}: \mathrm{Zn} / \mathrm{Ti} \mathrm{LDH}-\mathrm{CO}_{3}$ (intercalated with carbonate anion) and $\mathrm{Zn} / \mathrm{Ti} \mathrm{LDH}-\mathrm{DDS}$ (intercalated with DDS anion).

\section{Nanocomposite Preparation}

LDPE nanocomposites containing $\mathrm{Zn} / \mathrm{Ti} \mathrm{LDH}-\mathrm{CO}_{3}$ and $\mathrm{Zn} / \mathrm{Ti} \mathrm{LDH}-\mathrm{DDS}$ were prepared by the melt intercalation process. Firstly, a masterbatch containing LDH and LDPE-g-MAH in a 1:3 ratio was processed in an extruder micro-screw (with a capacity of $12 \mathrm{~g}$ ) at $180{ }^{\circ} \mathrm{C}$, with $100 \mathrm{rpm}$ for 6 minutes. Subsequently, the masterbatch was diluted in additive-free LDPE containing $1.0 \%$ of the LDH in an extruder micro-screw in the same conditions. The composites were named $\mathrm{PE}-\mathrm{LDH}-\mathrm{CO}_{3}$ and PE-LDH-DDS.

\section{Characterizations}

X-ray diffraction analysis of the fillers were performed using a Shimadzu 6000 diffractometer, using $\mathrm{CuK}_{\alpha}$ radiation $(\lambda=1.5418 \AA)$, operating at 30 $\mathrm{mA}$ and $40 \mathrm{kV}$. Samples were placed on glass sample holders and gently pressed to avoid displacement errors. The nanocomposite samples were also evaluated by XRD using $\mathrm{CuK}_{\alpha}$ radiation in the region of

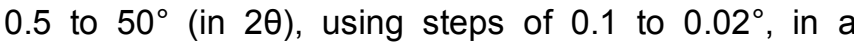
Bruker AXS diffractometer operating at $30 \mathrm{~mA}$ and 40 $\mathrm{kV}$.

Fourier-transform infrared spectra were obtained in an Equinox 55 FTIR spectrophotometer. The powder samples were mixed with $\mathrm{KBr}$ in the ratio of $1: 200$ (wt./wt.), and the mixture were pressed into tablet form.

Transmission electron microscopic (TEM) images and selected area electron diffraction analyzes (SAED) were obtained in a JEOL JEM 1200 EX-II (CME-UFPR) electronic microscope, with a voltage of $80 \mathrm{kV}$. The samples were dispersed in acetone, deposited onto the copper grids coated with amorphous carbon, and dried in the air. For the SAED measurements, gold was used as the standard for spot length measurements, and indexations were performed with the Gimp software.

Thermogravimetric analysis (TGA) was performed with a TA Instruments Q5000 analyzer under nitrogen flow, between 40 and $800{ }^{\circ} \mathrm{C}$ and at a heating rate of $10^{\circ} \mathrm{C} \mathrm{min}^{-1}$. 
Differential scanning calorimetric experiments were performed with a TA Instruments DSC Q1000 calorimeter, with temperatures ranging from -80 to $180^{\circ} \mathrm{C}$. First, the sample was submitted to heating to $180{ }^{\circ} \mathrm{C}$, to eliminate the polymer thermal history, and the first cooling and second heating were conducted at a rate of $10^{\circ} \mathrm{C} \mathrm{min}{ }^{-1}$.

The spectroscopy samples in the UV-Vis region were pressed and molded to $100 \mu \mathrm{m}$ in thickness. The films were measured by transmission mode by the Lambda 800 from Perkin Elmer equipment equipped with a $150 \mathrm{~mm}$ integration sphere (Labsphere) and an integration time of $0.36 \mathrm{~s}$.

The accelerated weathering of the samples was performed using Xenotest Alpha from Atlas according to DIN EN ISO U4892-2, which includes a constant UV exposure light, controlled temperature, $108 \mathrm{~min}$ dry phase cycle, with controlled humidity and $12 \mathrm{~min}$ phase cycle wet.

\section{RESULTS AND DISCUSSION}

\section{Zn/Ti LDH Characterizations}

X-ray diffractogram patterns (XRD) of $\mathrm{Zn} / \mathrm{Ti} \mathrm{LDH}$ $\mathrm{CO}_{3}$ (Figure 1a) presents a basal spacing value of 6.81 $\AA$, obtained from the basal reflection planes (003) and (006), and is consistent with intercalation of carbonate anion as described in Li et al. (2017) and Saber et al. $(2003)$ studies $[7,8]$. This basal spacing showed a little to a higher scattering angle in comparison with MgAlLDH $\left(\mathrm{d}_{003}=7.42 \mathrm{~nm}\right)$ [3]. This fact indicates that the incorporation of a $\mathrm{M}^{\mathrm{IV}}(\mathrm{Ti})$ in hydrotalcite structure resulted in a decrease in the basal distance, as demonstrated in Fang et al. (2019) and Li et al. (2016) studies $[3,5]$.It was also possible to observe some lowintensity peaks related to $\mathrm{Zn}(\mathrm{OH})_{2}$ (Figure 1a) [5].

After intercalation of the DDS anion, reflections corresponding to basal stacking were shifted to smaller angles. The basal distance of $38.09 \AA$ (basal planes (003) and (006)) is consistent with the intercalation of the organic anion (Figure 1b). Considering the brucite layer thickness $(4.8 \AA)$ and dodecyl sulfate anion size $(20.2 \AA)$ intercalated, one can estimate the basal spacing as $25 \AA$ [9]. This value is different from the basal distance obtained by $\mathrm{X}$-ray diffractogram (Figure 1b); this can be explained due to water molecules associated with the sulfate group and organic anion orientation and intercalation of bilayer of dodecyl sulfate anion in LDH interlayer space as demonstrated in Meyn et al. (1993) study [10].

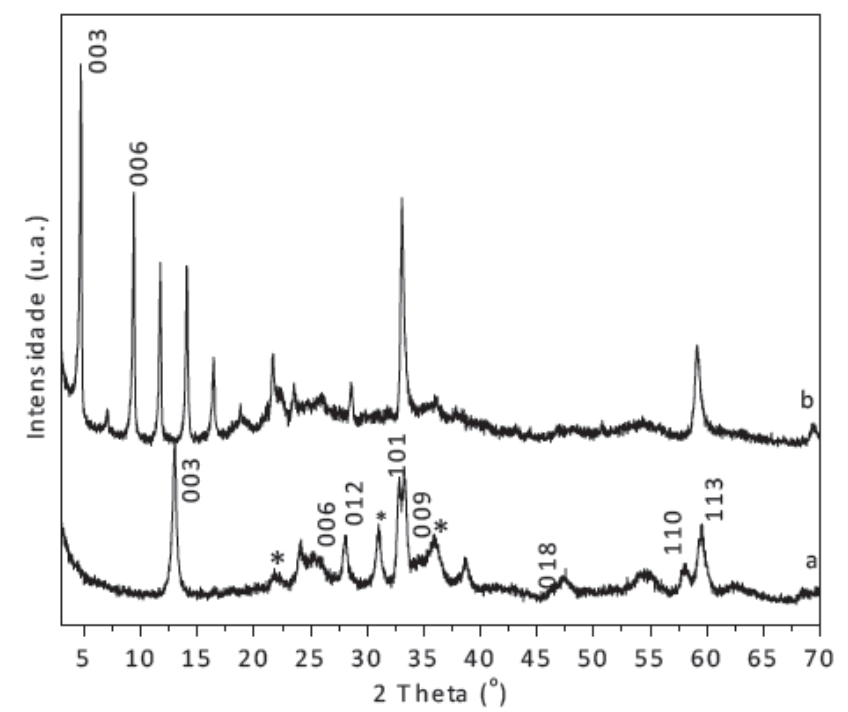

Figure 1: X-ray diffraction (XRD) patterns for the compounds: $\mathrm{Zn} / \mathrm{Ti} \mathrm{LDH}-\mathrm{CO}_{3}(\mathrm{a})$ and $\mathrm{Zn} / \mathrm{Ti} \mathrm{LDH}-\mathrm{DDS}$ (b). ${ }^{*} \mathrm{Zn}(\mathrm{OH})_{2}$.

Infrared region spectra (FTIR) for the samples $\mathrm{Zn} / \mathrm{Ti}$ $\mathrm{LDH}-\mathrm{CO}_{3}$ and $\mathrm{Zn} / \mathrm{Ti} \mathrm{LDH}-\mathrm{DDS}$ were presented in Figure 2. FTIR spectra show a broadband in the region of $3446 \mathrm{~cm}^{-1}$, attributed to the vibrations of hydroxyl groups that maintain multiple hydrogen bonds with water molecules in the host layers. The bend deformation of water molecules can be attributed to relatives bands at wavenumber $1620 \mathrm{~cm}^{-1}$ for both samples. Absorption bands below $719 \mathrm{~cm}^{-1}$, which are $696 \mathrm{~cm}^{-1}, 584 \mathrm{~cm}^{-1}$, and $455 \mathrm{~cm}^{-1}$, can be attributed to different $\mathrm{Zn}-\mathrm{O}$ stretching and $\mathrm{Zn}-\mathrm{OH}$ bending vibrations, and this result is in accordance with Zhang et al. (2017) results [11]. Bands in the region of 1497, 1385 , and $734 \mathrm{~cm}^{-1}$ can be attributed to the different vibrational modes of the $\mathrm{C}-\mathrm{O}$ bonds of the carbonate group. Bands around $1497 \mathrm{~cm}^{-1}$ refer to antisymmetric stretching ( 03 mode), and in region $734 \mathrm{~cm}^{-1}$ refers to axial deformation ( $\mathrm{v} 2$ and $\mathrm{v} 4$ modes) [12].

Considering the intercalation of dodecyl sulfate anion can observe typical bands of this surfactant salt $\mathrm{Zn} / \mathrm{Ti}$ LDH-DDS products (Figure 2b). Bands in the region of 2923 and $2854 \mathrm{~cm}^{-1}$ can be attributed to asymmetric and symmetric $\mathrm{CH}_{2}$ stretching vibration of the dodecyl sulfate chain. In the range of 1207-825 $\mathrm{cm}^{-1}$ is possible to observe bands relative to different vibrational and stretching modes of the sulfate group [11].

The thermal decomposition profile of the sample $\mathrm{Zn} / \mathrm{Ti} \mathrm{LDH}-\mathrm{CO}_{3}$ (Figure 3a) shows only one mass loss event related to dehydration, dihydroxylation of the layer structure, and the formation of $\mathrm{ZnO}$. 


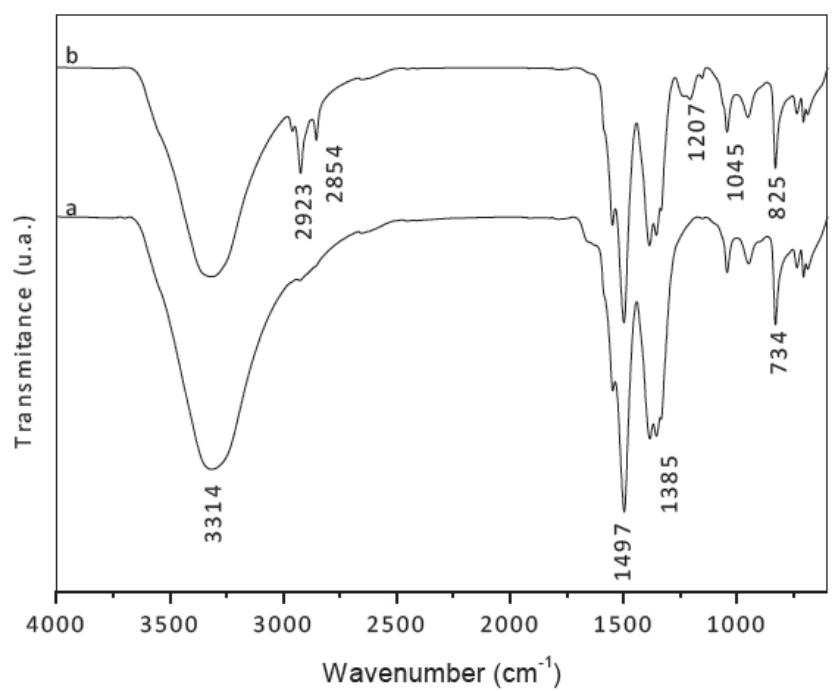

Figure 2: Infrared spectrum (FTIR) for the compounds: $\mathrm{Zn} / \mathrm{Ti}$ $\mathrm{LDH}_{-} \mathrm{CO}_{3}(\mathrm{a})$ and $\mathrm{Zn} / \mathrm{Ti} \mathrm{LDH}-\mathrm{DDS}(\mathrm{b})$.

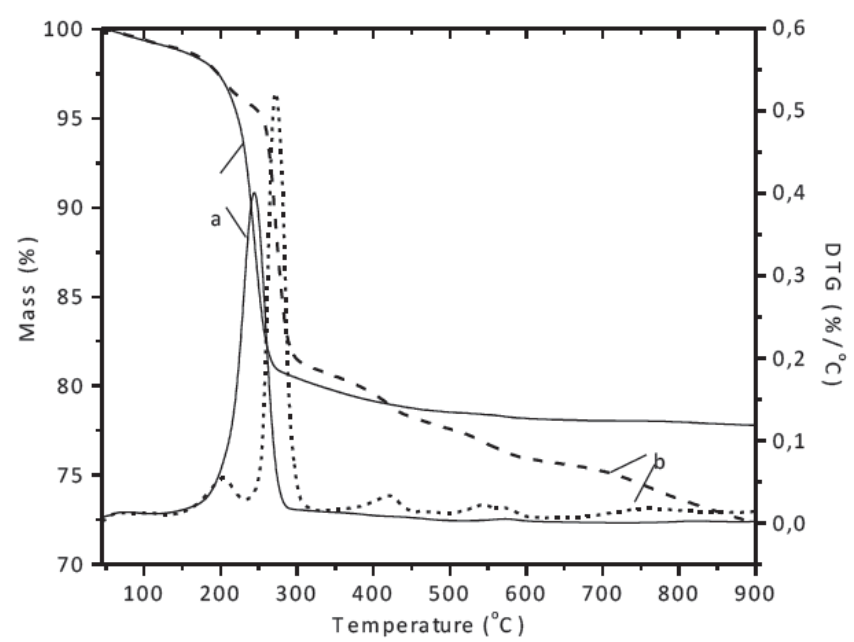

Figure 3: Thermal analysis (TGA/DTG) for the compounds: $\mathrm{Zn} / \mathrm{Ti} \mathrm{LDH}-\mathrm{CO}_{3}(\mathrm{a})$ and $\mathrm{Zn} / \mathrm{Ti} \mathrm{LDH}-\mathrm{DDS}$ (b).

In the thermal decomposition of the sample $\mathrm{Zn} / \mathrm{Ti}$ LDH-DDS (Figure $3 \mathbf{b}$ ), more complex mass loss events

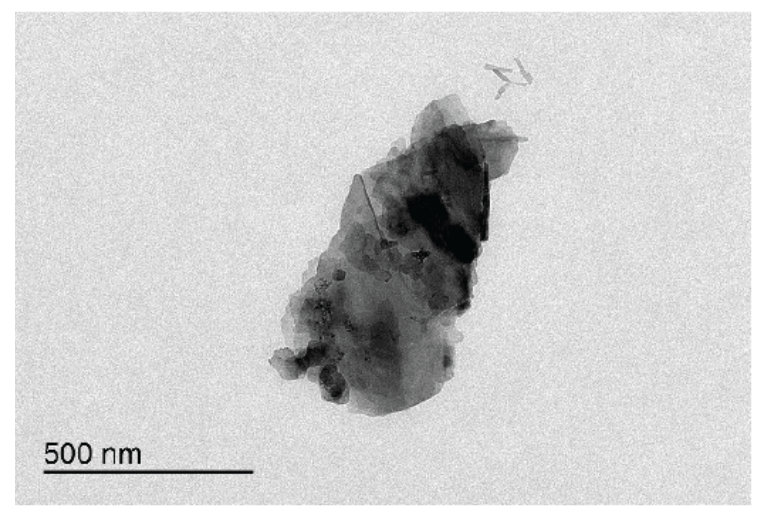

(a) were observed. The first loss of mass, observed in the region up to approximately $250{ }^{\circ} \mathrm{C}$, occurred the loss of water molecules. Between $250{ }^{\circ} \mathrm{C}$ and approximately $600{ }^{\circ} \mathrm{C}$ the loss of mass was related to the burning of organic matter, which corresponded to the three events of the DTG curve. Between 700 and $900{ }^{\circ} \mathrm{C}$, the formation of oxides related to the last event of the DTG curve occurred.

The transmission electron microscopic (TEM) images of $\mathrm{Zn} / \mathrm{Ti}$ LDH-DDS (Figure 4a) show a typical plate-like morphology of varying dimensions and nanometric thicknesses. It was observed homogeneous regions along the layer structure, and this suggests the existence of single crystals and resistance to electron beam decomposition allowed the SAED spectrum to be obtained. The obtained $\mathrm{Zn} / \mathrm{Ti}$ LDH-DDS compound was found with LDH crystallographic structure as observed for SAED and TEM analysis in Jaerger et al. (2019) and Hobbs et al. $(2018)$ studies $[9,13]$ and its associated SAED pattern (Figure 4b) reveal (100), (110) and(010) crystallographic plans.

\section{Nanocomposite Characterizations}

Diffractograms in Figure 5a-b show diffraction peaks in the region of 20 to 25 degrees (in 20), attributed to the crystallographic planes (110) and (200) of the polyethylene [9].

The X-ray diffractogram for the composite PE-LDH$\mathrm{CO}_{3}$ (Figure 5c, d) did not show any diffraction peak about the layer stacking planes due to its low concentration (only $1.0 \%$ ). However, it is believed that because it is a hydrophilic compound, which does not have a good interaction with the polymer, it has preserved its structure in the polymeric matrix.

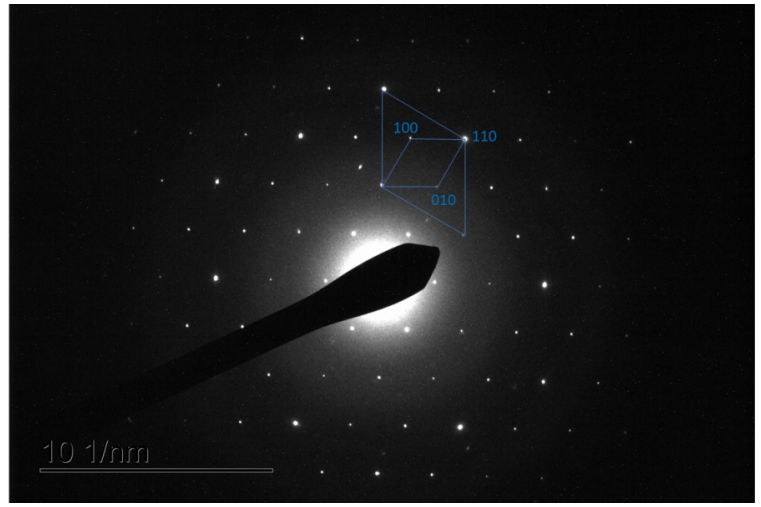

(b)

Figure 4: TEM image for Zn/Ti LDH-DDS (a) and SAED spectrum with representation of the unit cell. 


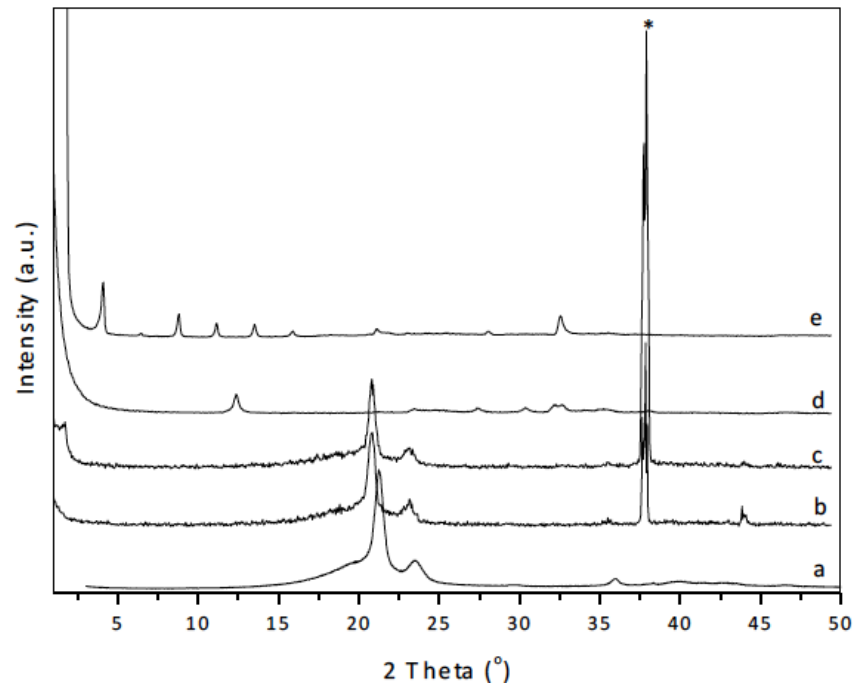

Figure 5: X-ray diffraction (XRD) patterns for the compounds: neat LDPE (a), PE-LDH-CO 3 (b), PE-LDH-DDS (c), Zn/Ti $\mathrm{LDH}_{-} \mathrm{CO}_{3}(\mathrm{~d})$, and $\mathrm{Zn} / \mathrm{Ti} \mathrm{LDH}-\mathrm{DDS}(\mathrm{e})$. *Al.

On the other hand, the diffractogram for the composite containing the LDH intercalated with dodecyl sulfate anion. It is possible to verify the presence of a

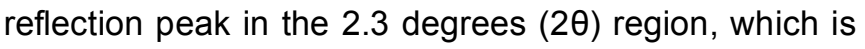
related to reflection peaks attributed to the basal stacking of the LDH (Figure $\mathbf{5 d}$, e). As the other peaks are not observed, it can be said that the delamination of the layer compound occurred in the polymeric matrix. Similar results were obtained in our previous study [14] for organophilic LDH of Ni/Al and Co/Al. This fact indicates that during the extrusion process with no shear force was applied, the long chains of the polymer interact with the dodecyl sulfate intercalated in LDH due to high affinity and cause expansion, delamination/exfoliation of the layered crystals of LDH in polymer matrix [14].

The results of the differential scanning calorimetry (DSC) curves (Figure 6, Table 3) show that the $\mathrm{Zn} / \mathrm{Ti}$ $\mathrm{LDH}$ added to the polymer did not change the melting and crystallization temperature values $\left(T_{c}\right.$ and $T_{m}$, respectively). However, the melting and crystallization enthalpy $\left(\Delta \mathrm{H}_{\mathrm{m}}\right.$ and $\Delta \mathrm{H}_{\mathrm{c}}$, respectively) were reduced by about $8 \mathrm{~J} \mathrm{~g}^{-1}$ when hydrophilic and hydrophobic LDH were added compared to pure polymer. Studies show that lowering the crystallization enthalpy value can be attributed to good interaction between the filler and polymer matrix, making it difficult to form crystalline domains in the polymer [9]. Reduction of the enthalpies was also observed in our previous study [15] for LDPE nanocomposite containing organophilic $\mathrm{Zn} / \mathrm{Al}$ and $\mathrm{Co} / \mathrm{Al}$ $\mathrm{LDHs}$, and these results can be explained due to the reduction of LDPE chain mobility and hindering the formation of polymer crystal domain, a fact attributed to the good interaction between filler $\mathrm{Zn} / \mathrm{Ti} \mathrm{LDH}$ and polymer matrix interfaces [15].

An increase in polymers' temperature can imply physical and chemical degradation, so thermal property
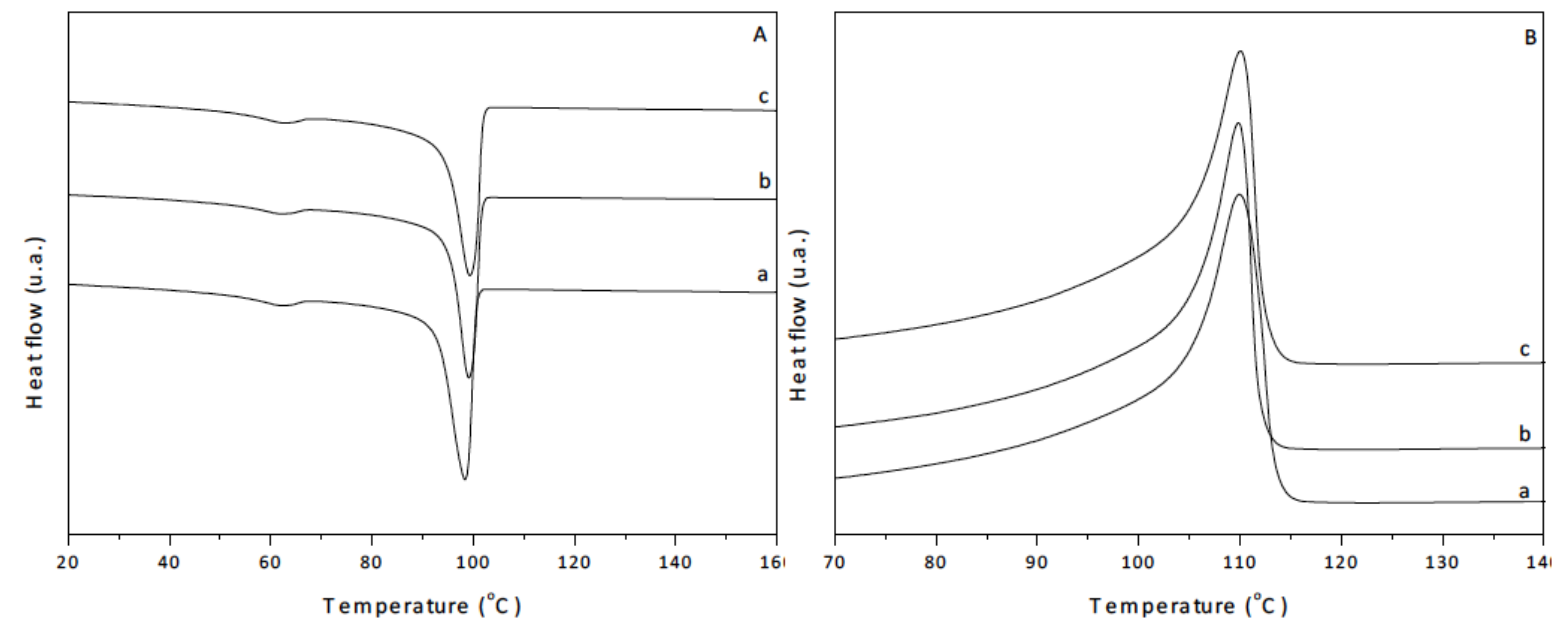

Figure 6: Differential scanning calorimetry (DSC) curves: A - first cooling and B - second heating for the samples: neat LDPE (a), PE-LDH-CO 3 (b) and PE-LDH-DDS (c).

Table 3: Thermal Parameters for LDPE Composites Containing Zn/Ti LDH

\begin{tabular}{|c|c|c|c|c|}
\hline Samples & $\mathrm{T}_{\mathrm{m}}\left({ }^{\circ} \mathrm{C}\right)$ & $\Delta \mathbf{H}_{\mathrm{m}}\left(\mathrm{J} \mathrm{g}^{-1}\right)$ & $\mathrm{T}_{\mathrm{c}}\left({ }^{\circ} \mathrm{C}\right)$ & $\Delta H_{\mathrm{c}}\left(\mathrm{J} \mathrm{g}^{-1}\right)$ \\
\hline PE-LDH-CO ${ }_{3}$ & 99.1 & -147.8 & 109.8 & 148.2 \\
\hline PE-LDH-DDS & 99.3 & -149.4 & 110.0 & 149.4 \\
\hline
\end{tabular}


evaluation is required. Thermal degradation behavior of nanocomposites and neat LDPE were studied using TGA, and the data showed that addition on just $1 \%$ of both LDH causes an increase of $5.43{ }^{\circ} \mathrm{C}$ (obtained by onset temperature - $T_{0.5}$ ) in thermal stability of LDPE nanocomposite (Figure $\mathbf{7 b}$-c). A decrease of the thermal stability with the addition of Ni/Al-LDH intercalated with dodecyl sulfate in LDPE polymer matrix was also obtained in our previous study [9]. And the results can be explained that the thermal stability of the nanocomposite is due to thermally stable charcoal formation from LDH degradation, which causes the preventing of further polymer degradation [9].

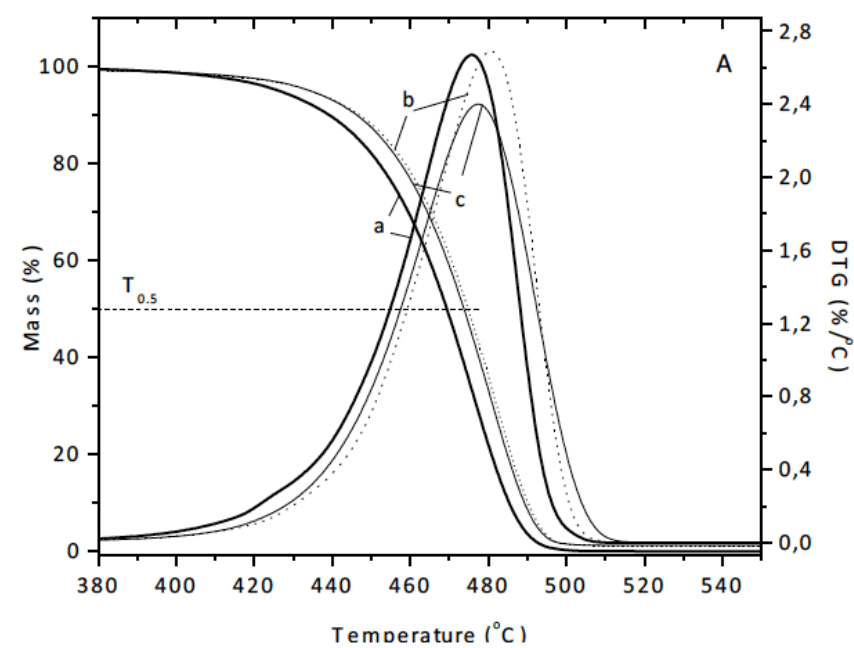

Figure 7: Thermal analysis (TGA/DTG) for the compounds: neat LDPE (a), PE-LDH-CO 3 (b), and PE-LDH-DDS (c).

UV-Vis spectra of LDPE composite containing Zn/Ti LDH-DDS (Figure 8c) show a higher absorption region (maximum at $280 \mathrm{~nm}$ ) than other nanocomposite and neat polymer; this result indicate that intercalation of DDS anion enhances UV absorption properties. $\mathrm{Zn} / \mathrm{Ti}$ LDH-DDS absorbs more light than the $\mathrm{Zn} / \mathrm{Ti} \mathrm{LDH}-\mathrm{CO}_{3}$ due to the enhanced interlayer distance in the presence of DDS in the basal space of LDH, which further the intercalation process of polymer chains within the interlayer regions of $\mathrm{LDH}$.

The van der Waals interlayer bonds are relatively weak of the LDH, which allows excellent interlayer anion exchange capability. The Mohapatra and Parida's (2016) study [4] shows that the space interlayer plays an important role in the better efficiency of photocatalytic activities. Interlayer LDH water molecules and hydronium ions play a key role in increasing photoactivity with efficient charge separation. Due to the ease with which anions are interchangeable in the interlayer space, LDH is able to accommodate bulky anions such as dodecyl sulfate. Large interlayer anions increase the photocatalytic activity when compared to the original's layered hydroxides. This is due to the interlayer space facilitating the reaction between photogenerated charge carriers and reagent molecules that supply the charge recombination [4].

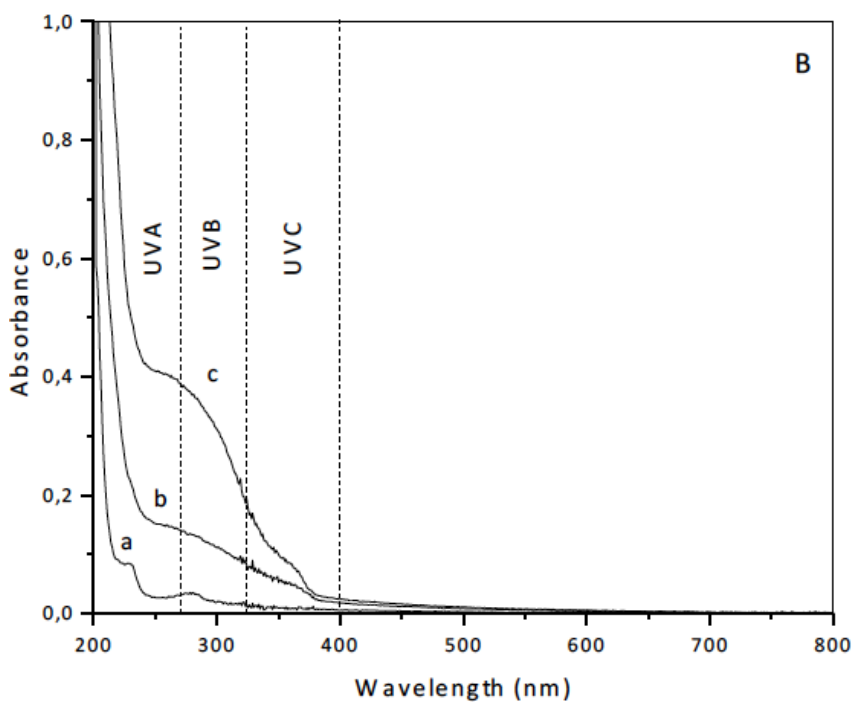

Figure 8: UV-Vis spectra for the compounds: neat LDPE (a), $\mathrm{PE}-\mathrm{LDH}-\mathrm{CO}_{3}(\mathrm{~b})$, and PE-LDH-DDS (c).

\section{CONCLUSIONS}

Thereby, the current study presents the following conclusions:

1. X-Ray diffractograms present a good basal peaks sequence for LDH structure containing $\mathrm{Zn}$ and $\mathrm{Ti}$ metals, indicating success in their synthesis where $\mathrm{Zn} / \mathrm{Ti} \mathrm{LDH}-\mathrm{CO}_{3}$ presents a basal spacing value of $6.81 \AA$ and $\mathrm{Zn} / \mathrm{Ti} \mathrm{LDH}$ DDS presents the basal distance of $38.09 \AA$.

2. FTIR spectrum confirmed the formation of the layered compound due to the presence of typical bands for carbonate anions and dodecyl sulfate anions demonstrating success of intercalation of the two counter ions.

3. TG decomposition profile of the sample $\mathrm{Zn} / \mathrm{Ti}$ $\mathrm{LDH}-\mathrm{CO}_{3}$ shows only one mass loss event, while the compound $\mathrm{Zn} / \mathrm{Ti} \mathrm{LDH}-\mathrm{DDS}$ present complex mass loss events, related owing the presence of different counter ion of the layered compound.

4. The TEM images of $\mathrm{Zn} / \mathrm{Ti} \mathrm{LDH}$ show a typical plate-like morphology of varying dimensions and nanometric thicknesses. 
5. Thermal properties of LDPE composites containing both $\mathrm{Zn} / \mathrm{Ti} \mathrm{LDH}-\mathrm{CO}_{3}$ and $\mathrm{Zn} / \mathrm{Ti} \mathrm{LDH}$ DDS show improvement of this property with the addition of only $1 \%$ of the filler.

6. LDPE composite containing dodecyl sulfate anion intercalated in LDH presented a very well dispersion nanocomposite as demonstrated by X-Ray diffractograms and DSC results, and this fact indicates that intercalation of DDS anion enhances UV absorption properties compared with $\mathrm{Zn} / \mathrm{Ti} \mathrm{LDH}-\mathrm{CO}_{3}$. This observation is due to the enhanced interlayer distance in the presence of DDS in the basal space of LDH, furthering the intercalation process of polymer chains within the interlayer regions of $\mathrm{LDH}$.

\section{ACKNOWLEDGEMENTS}

The authors thanks the Conselho Nacional de Desenvolvimento Científico e Tecnológico (CNPq), Coordenação de Aperfeiçoamento de Pessoal de Nível Superior (CAPES) and Fundação Araucária for financial support. Especial thanks also to prof. Andreas Leuteritz and prof. Gert Heinrich from Leibniz Institut für Polymerforschung Dresden, Germany, where part of this work was developed. S.J. also thanks CNPq Ciências sem Fronteiras for the Ph.D. grant during the stay in Germany.

\section{REFERENCES}

[1] Ovali S, Sancak E. Investigating the effect of the aging process on LDPE composites with UV protective additives. Journal of Thermoplastic Composite Materials 2020; 1-19. https://doi.org/10.1177/0892705720941908

[2] Naseem S, Lonkar SP, Leuteritz A, Labuschagné FJWJ. Different transition metal combinations of LDH systems and their organic modifications as UV protecting materials for polypropylene (PP). RSC Advanced 2018; 8: 29789-29796. https://doi.org/10.1039/C8RA05447A

[3] Fang $P$, Wang $Z$, Wang. Enhanced photocatalytic performance of ZnTi-LDHs with morphology control. Cryst Eng Comm 2019; 21: 7025-7031. https://doi.org/10.1039/C9CE01406C

[4] Mohapatra L, Parida K. A review on the recent progress, challenges and perspective of layered double hydroxides as promising photocatalysts. Journal of Materials Chemistry A 2016; 4: 10744-10766. https://doi.org/10.1039/C6TA01668E
[5] Wang XR, Li Y, Tang LP, Gan W, Zhou W, Zhao YF, Bai DS. Fabrication of $\mathrm{Zn}$-Ti layered double hydroxide by varying cationic ratio of $\mathrm{Ti}^{4+}$ and its application as UV absorbent. Chinese Chemical Letters 2017; 28: 394-399. https://doi.org/10.1016/j.cclet.2016.09.002

[6] Lee Y, Choi JH, Jeon HJ, Choi KM, Lee JW, Kang JK. Titanium-embedded layered double hydroxides as highly efficient water oxidation photocatalysts under visible light. Energy \& Environmental Science 2011; 4: 914-920.

[7] Li Y, Tang L, Ma X, Wang X, Zhou W, Bai D. Synthesis and characterization of $\mathrm{Zn}-\mathrm{Ti}$ layered double hydroxide intercalated with cinnamic acid for cosmetic application. Journal of Physics and Chemistry of Solids 2017; 107: 62-67. https://doi.org/10.1016/j.jpcs.2017.02.018

[8] Saber O, Tagaya H. New Layered Double Hydroxide, $\mathrm{Zn}-\mathrm{Ti}$ LDH: Preparation and Intercalation Reactions. Journal of Inclusion Phenomena and Macrocyclic Chemistry 2003; 45: 109-116.

https://doi.org/10.1023/A:1023078728942

[9] Jaerger $S$, Wypych $F$. Thermal and flammability properties influenced by $\mathrm{Zn} / \mathrm{Al}, \mathrm{Co} / \mathrm{Al}$, and $\mathrm{Ni} / \mathrm{Al}$ layered double hydroxide in low-density polyethylene nanocomposites. Journal of Applied Polymer Science 2019; 137: 48737. https://doi.org/10.1002/app.48737

[10] Meyn M, Beneke K, Lagaly G. Anion exchange reaction of hydroxyl double salts. Inorganic Chemistry 1993; 32: 12091215.

https://doi.org/10.1021/ic00059a030

[11] Zhang D, Liu X, Wan H, Zhang N, Liang S, Ma R, Qiu G. Large-Scale Preparation, Chemical Exfoliation, and Structural Modification of Layered Zinc Hydroxide Nanocones: Transformation into Zinc Oxide Nanocones for Enhanced Photocatalytic Properties. ACS Sustainable Chemistry Engineer 2017; 5: 5869-5879.

https://doi.org/10.1021/acssuschemeng. 7 b00597

[12] Rives V, Kannan S. Layered double hydroxides with the hydrotalcite-type structure containing $\mathrm{Cu}^{2+}, \mathrm{Ni}^{2+}$ and $\mathrm{Al}^{3+}$ Journal of Materials Chemistry 2000; 10: 489-495. https://doi.org/10.1039/A908534C

[13] Hobbs C, Jaskaniec S, McCarthy EK, Dowing C, Opelts K, Güth K, Shmeliov A, Mourad MCD, Mendel K, Nicolosi V. Structural transformation of layered double hydroxides: an in situ TEM analysis. Npj 2D Materials and Application 2018; 2: 4. https://doi.org/10.1038/s41699-018-0048-4

[14] Jaerger S, Zawadzki SF, Leuteritz A, Wypych F. New Alternative to Produce Colored Polymer Nanocomposites: Organophilic $\mathrm{Ni} / \mathrm{Al}$ and $\mathrm{Co} / \mathrm{Al}$ Layered Double Hydroxide as Fillers into Low-Density Polyethylene. Journal of the Brazilian Chemical Society 2017; 28: 2391-2401.

https://doi.org/10.21577/0103-5053.20170093

[15] Jaerger S, Leuteritz A, Freitas RA, Wypych F. Rheological properties of low-density polyethylene filled with hydrophobic Co(Ni)-Al layered double hydroxides. Polimeros 2019; 29: e2019007.

https://doi.org/10.1590/0104-1428.09717 